\title{
Mathematical modeling of an effect of refractory metal nanopowders on the strength of concrete
}

\author{
$Y u$ Papkova $^{1,}{ }^{*}, S$ Papkov $^{1}$, and $V$ Gavrish $^{1}$ \\ ${ }^{1}$ Sevastopol State University, Sevastopol, 299053, Russia
}

\begin{abstract}
The quality of concrete and the reliability of its exploitation in structures and structures are largely determined by such characteristic as strength. Additives increasing the strength can significantly improve the quality of concrete. The aim of this work is mathematical modeling of the effect of refractory metal nanopowders on the strength of concrete. Regression equations of the first and second orders are constructed, which adequately find the dependence of the compressive strength of concrete on the input parameters. For presented model the optimal values of the concentrations of refractory metal nanopowders have been calculated.
\end{abstract}

\section{Introduction}

The construction industry is one of the most dynamically developing segments of the Russian economy. Modern trends in the development of materials science in construction are closely related to the development of new resource-saving technologies for production concrete, with improved performance and durability. At the same time, the lack of material resources, developed in a number of regions, urgently requires increasing the profitability of the industry production of building materials due to the wide use as local resources and manmade materials. The downside of this trend is that the use of local substandard raw materials leads to a decrease in the strength of the cement construction composites.

At the same time, the quality of concrete and the reliability of its using in structures and structures are largely determined by such characteristic as strength. Strength is understood as the ability of a material to resist destruction as a result of external loading. This integral characteristic strongly depends on the mechanical and chemical properties of the material (concrete components), on the methods of concrete preparation and the exploitation of the structure. Some theoretical aspects of the dependence of the strength of composite materials on their physical and mechanical properties are considered in [1-4]. Nevertheless, in modern building materials science there is no complete theory that allows us to calculate its strength based on the given properties of concrete ingredients.

One of the possible solutions to the problem of improving the quality of concrete is the use of a limited number of highly active additives. As well known, concrete resists compression well and is much worse in tension. Due to this, additives, leading to an increase in strength can significantly improve the quality of the concrete. The experimentally demonstrated [5] that micro- and nanomodifiers (nanopowders) are the most promising

*Corresponding author: yulia.papkova@gmail.com 
among the possible additives. A significant limitation of this approach is the high cost of nanopowders, the lack of technologies for their mass production, which does not allow them to be used as additives on an industrial scale.

However, new technologies for the production of nanopowders make it possible to include the use of nanopowders in the cycle of concrete production in the future [6]. Thus, the aim of this work is mathematical modeling of the effect of refractory metal nanopowders on the strength of concrete.

\section{Methods}

The purpose of experimental studies is to study the effect of the addition nanopowders of refractory metal on the strength of a concrete sample (size $100 \times 100 \times 100 \mathrm{~mm}$ ) at the age of 28 days of normal hardening ( $R^{28}, \mathrm{MPa}$ ) under compression in order to select the optimal amount of additives for which the concrete has the desired properties. Methods of mathematical planning of the experiment will make it possible to create a mathematical empirical model, depicting the influence of incoming parameters, that is, to form a response function in the form

$$
y=f\left(x_{1}, x_{2}, \ldots, x_{n}\right)
$$

where $x_{1}, x_{2}, \ldots, x_{n}$ - are the factors of the experiment.

It is usually assumed in experimental analysis of building structures that the response function (concrete compressive strength) is a random variable with a normal distribution law. On this basis, regression analysis methods are used when testing statistical hypotheses about the response function. Tables 1, 2 present the results of the characteristics of the homogeneity of concrete modified with various powders of refractory metals. It should be noted that statistical values are estimated as averages due to the limited sampling.

Table 1. Results of homogeneity characteristics of concrete modified with nanopowder $W C$, in strength.

\begin{tabular}{|c|c|c|c|c|}
\hline $\begin{array}{c}\text { Nanopowder } \\
\text { content } W C, \\
\%\end{array}$ & $\begin{array}{c}\text { The range of } \\
\text { single values } \\
W_{m}\end{array}$ & $\begin{array}{c}\text { Average quadratic } \\
\text { deviation } S_{m}\end{array}$ & $\begin{array}{c}\text { The coefficient } \\
\text { of variation } V_{m}, \\
\%\end{array}$ & $\begin{array}{c}\text { Actual class, } \\
B_{\phi}\end{array}$ \\
\hline 0 & 0.711364 & 0.420925 & 4.088007 & 8.237275 \\
\hline 1 & 1.514205 & 0.895979 & 6.961364 & 10.29659 \\
\hline 2 & 0.302841 & 0.179196 & 1.344809 & 10.66 \\
\hline 3 & 0.605682 & 0.358392 & 2.320455 & 12.35591 \\
\hline
\end{tabular}

Table 2. Results of homogeneity characteristics of concrete modified with nanopowder $\mathrm{WO}_{3}$, in strength.

\begin{tabular}{|c|c|c|c|c|}
\hline $\begin{array}{c}\text { Nanopowder } \\
\text { content } \\
W O_{3}, \%\end{array}$ & $\begin{array}{c}\text { The range of } \\
\text { single values } \\
W_{m}\end{array}$ & $\begin{array}{c}\text { Average quadratic } \\
\text { deviation } S_{m}\end{array}$ & $\begin{array}{c}\text { The coefficient } \\
\text { of variation } V_{m}, \\
\%\end{array}$ & $\begin{array}{c}\text { Actual class, } \\
B_{\phi}\end{array}$ \\
\hline 0 & 0.711364 & 0.420925 & 4.088007 & 8.237275 \\
\hline 1 & 0.605682 & 0.358392 & 3.034441 & 9.448639 \\
\hline 2 & 0.302841 & 0.179196 & 1.461027 & 9.812048 \\
\hline 3 & 0.908523 & 0.537588 & 4.863419 & 8.842957 \\
\hline
\end{tabular}

The analysis of the homogeneity of concrete (tables 1, 2) showed, that the intra-batch coefficient of variation is in the range of less than $5 \%$. Thus, the quality of production and testing of samples can be considered satisfactory. 


\section{Results of modeling}

Let us carry out mathematical modeling of the influence of parameters on the strength of concrete under compression by the first-order planning method, where first-order polynomials $y=b_{0}+b_{1} x_{1}+b_{2} x_{2}+\ldots+b_{n} x_{n}$ are chosen as approximating functions.

The working composition of concrete samples without additives had the following ratio: Cement (C): Sand (S): Crushed stone (St): Water (W) = 1: 2.4: 4.3: 0.6.

During the experiment the mixes with different contents of the modifier $(\mathrm{H})$ have been prepared for the same ratio of the working composition of concrete. The following parameters were selected as input parameters have effect on strength of concrete: x1 - ratio $\frac{S+N}{C+S t}$ in the range of $0.454 \ldots 0.458 ; \mathrm{x} 2$ - ratio $\frac{W}{C}$ within $0.59 \ldots 0.61$. The number of experiences in first-order planning is $N_{0}=2^{n}=4$. The first-order planning results are shown in Table 3 .

Table 3. Experimental results with the addition of refractory metal nanopowder.

\begin{tabular}{|c|c|c|c|c|c|c|}
\hline \multirow{3}{*}{$\begin{array}{c}\text { Experiment } \\
\text { number }\end{array}$} & \multicolumn{2}{|c|}{ Initial values } & \multicolumn{2}{|c|}{ Code values } & \multirow{3}{*}{$\begin{array}{l}\bar{R}^{28} \\
\text { WC }\end{array}$} & \multirow{3}{*}{$\begin{array}{l}\bar{R}^{28} \\
\mathbf{W O}_{3}\end{array}$} \\
\hline & $S+N$ & $W$ & & & & \\
\hline & $\overline{C+S t}$ & $\bar{C}$ & $\mathbf{X}_{1}$ & $\mathbf{X}_{2}$ & & \\
\hline 1 & 0,454 & 0,59 & -1 & -1 & 12,870 & 11,810 \\
\hline 2 & 0,458 & 0,61 & +1 & +1 & 15,445 & 10,448 \\
\hline 3 & 0,458 & 0,59 & +1 & -1 & 15,444 & 10,447 \\
\hline 4 & 0,454 & 0,61 & -1 & +1 & 12,871 & 11,811 \\
\hline
\end{tabular}

The hypothesis of the homogeneity of the dispersion is verified by using the Cochran test, its value is calculated by the formula:

$$
G_{p}=\frac{S_{\max }^{2}}{\sum_{k=1}^{N_{0}} S_{k}^{2}}
$$

where $S_{k}^{2}$ is the estimate variance of experiment $k, S_{\max }^{2}$ is a maximum of the calculated variances.

The calculated value of the Cochran test is compared with the table value $G_{T}$ $\left(G_{p} \leq G_{T}\right)$, which is at confidence level $P$ with degrees of freedom of numerator $f_{1}=n-1$ and denominator $f_{2}=N_{0}$.

For the experiments, each of which included 3 parallel experiments $G_{p}=0,788$, he hypothesis about the homogeneity of variances is can be accepted on $1 \%$ significance level, since the experimental value of the criterion does not exceed the tabular value.

Values of the coefficients $b_{i}$ in the regression equation can be found as follows 


$$
b_{i}=\frac{\sum_{k=1}^{N_{0}} x_{i k} \bar{y}_{k}}{N_{0}} i=0, \ldots, n,
$$

where $x_{0}$ is a fictive variable, which is introduced to obtain complete symmetry; $x_{0 k}=+1$ for all values $k=1, \ldots, N_{0}$.

Images of the surface were obtained (Fig. 1), described by objective functions. $Y_{1}=R^{28}(W C)$ and $Y_{2}=R^{28}\left(W O_{3}\right)$.
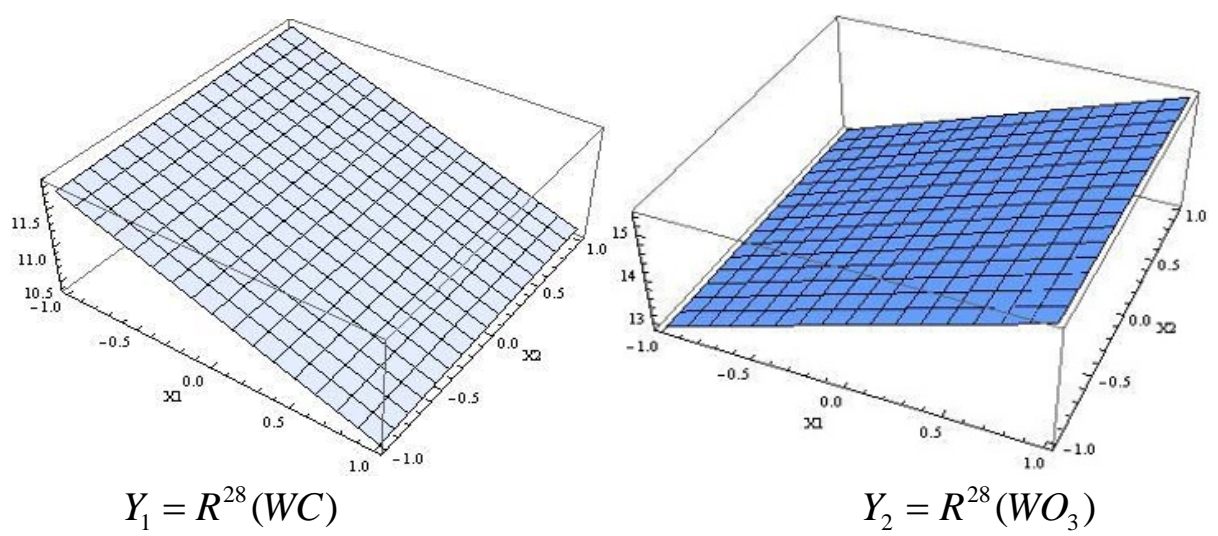

Fig. 1. Linear approximation of influence on the parameters on concrete strength.

Let us carry out mathematical modeling of the effect of parameters on the strength of concrete under compression by the second-order planning method, where second-order polynomials are chosen as approximating functions $y=b_{0}+b_{1} x_{1}+b_{2} x_{2}+b_{12} x_{1} x_{2}+b_{11} x_{1}^{2}+b_{22} x_{2}^{2}$.

The number of second-order orthogonal compositional planning experiments is calculated by the formula $N=2^{n}+2 n+1$. Plan parameter values are calculated as following

$$
a=\sqrt{\frac{N_{0}}{N}}, \alpha=\sqrt{\frac{1}{2}\left(\sqrt{N N_{0}}-N_{0}\right)} \text { is "star" shoulder. }
$$

Second order planning results $N=9$ with parameters $a=\frac{2}{3}, \alpha=1$ are given in Table 4 .

Table 4. Experimental results with the addition of refractory metal nanopowder.

\begin{tabular}{|c|c|c|c|c|c|c|c|}
\hline \multirow{2}{*}{$\begin{array}{c}\text { Experiment } \\
\text { number }\end{array}$} & \multicolumn{2}{|c|}{$\begin{array}{c}\text { Code } \\
\text { values }\end{array}$} & $\boldsymbol{x}_{\mathbf{1}} \boldsymbol{x}_{\mathbf{2}}$ & $x_{1}^{\prime}=x_{1}^{2}-a$ & $x_{2}^{\prime}=x_{2}^{2}-a$ & $\begin{array}{c}\bar{R}^{28}, \\
\mathbf{W C}\end{array}$ & $\begin{array}{c}\bar{R}^{28} \\
\mathbf{W O}_{\mathbf{3}}\end{array}$ \\
\hline & $\boldsymbol{x}_{\mathbf{1}}$ & $\boldsymbol{x}_{\mathbf{2}}$ & & $1 / 3$ & $1 / 3$ & 12,870 & 11,810 \\
\hline 1 & -1 & -1 & 1 & $1 / 3$ & $1 / 3$ & 15,445 & 10,448 \\
\hline 2 & +1 & +1 & 1 & $1 / 3$ & $1 / 3$ & 15,444 & 10,447 \\
\hline 3 & +1 & -1 & -1 & $1 / 3$ & $1 / 3$ & 12,871 & 11,811 \\
\hline 4 & -1 & +1 & -1 & $1 / 3$ & $-2 / 3$ & 12,870 & 11,810 \\
\hline 5 & -1 & 0 & 0 & $1 / 3$ & $-2 / 3$ & 15,445 & 10,448 \\
\hline 6 & +1 & 0 & 0 & $1 / 3$ & & & \\
\hline
\end{tabular}




\begin{tabular}{|l|c|c|c|c|c|c|c|}
\hline 7 & 0 & -1 & 0 & $-2 / 3$ & $1 / 3$ & 13,224 & 11,911 \\
\hline 8 & 0 & +1 & 0 & $-2 / 3$ & $1 / 3$ & 13,225 & 11,912 \\
\hline 9 & 0 & 0 & 0 & $-2 / 3$ & $-2 / 3$ & 13,224 & 11,911 \\
\hline
\end{tabular}

The above-mentioned formulas are used to calculate the coefficients of the second order regression equation.

The significance of the regression coefficients can be determined by the Student's t-test. For each coefficient, the calculated value of the Student's criterion is determined as following

$$
t_{i p}=\frac{\left|b_{i}\right| \sqrt{N}}{S_{\bar{y}}}
$$

\[ S_{\bar{y}}=\sqrt{\frac{S_{y}^{2}}{m}}, \text { m is number of parallel experiments, } \]
where
single measurement of the output parameter.

Calculated value of the Student's criterion is compared with tabulated $t_{T}$, which can be found with help of the confidence probability $\mathrm{P}$ and the number of degrees of freedom $f=N(m-1)$

After verifying the significance of the coefficients, images of surfaces of the objective functions (Fig. 2) were constructed $Y_{1}=R^{28}(W C)_{\text {и }} Y_{2}=R^{28}\left(W O_{3}\right)$.
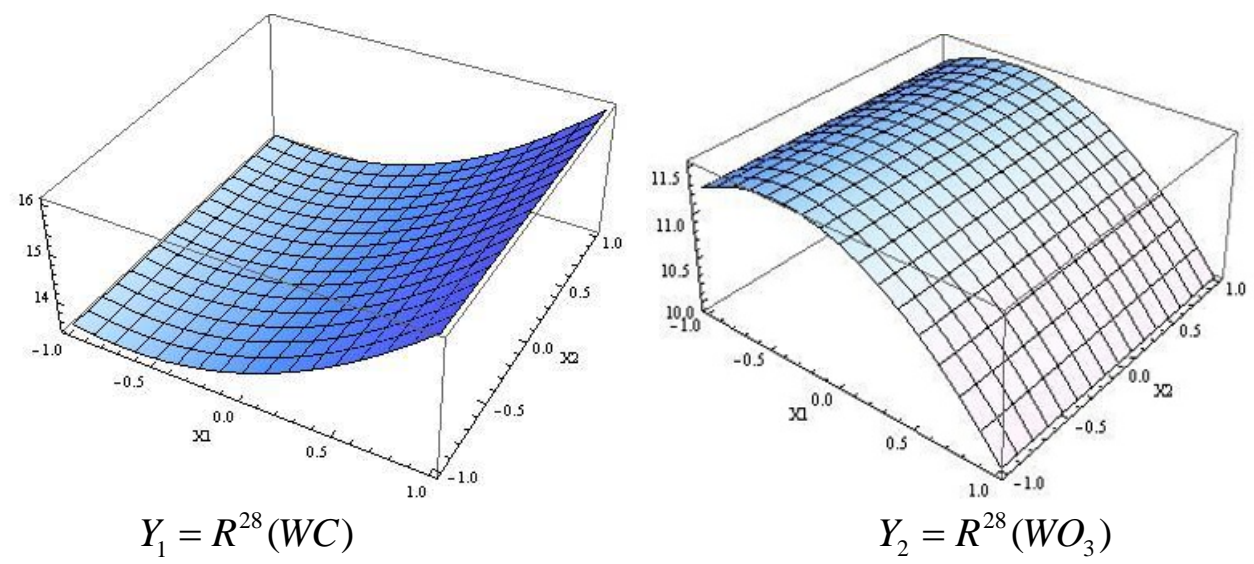

Fig. 2. Quadratic approximation of influence on the parameters on concrete strength.

\section{Conclusions}

The obtained regression equations of the first and second orders allow us to find adequately the dependence of the concrete compressive strength on the ratio of the input parameters $\mathrm{x} 1$ and $\mathrm{x} 2$. The optimal values of the concentration of nanopowders are calculated as: $2.95 \%$ $W C, 1.72 \% \mathrm{WO}_{3}$. According to presented modeling, nanopowder $\mathrm{WC}$ is the optimal additive to concrete that increases its operational properties. 


\section{Acknowledgments}

The study was carried out with the financial support of the Russian Foundation for Basic Research, scientific project No. 18-43-920001 r-a.

\section{References}

1. Mehta P K, Monteiro P J 2006 Concrete-Structure, Properities and Materials (Berkeley: University of California) p 684

2. Shah S P, Ahmad S H 1994 High perfomance concrete: Properities and applications (McGraw-Hill, Inc) p 403

3. Chousidis N, Ioannou I, Batis G 2018 Construction and Building Materials 158 708718

4. Van Lam, T, Bulgakov, B, Bazhenov, Y, Aleksandrova O, Anh P N 2018 IOP Conference Series: Materials Science and Engineering 365(3) 8

5. Jalal M, Pouladkhan A, Harandi OF, Jafari D 2015 Construction and Building Materials 94 90-104

6. Gavrish V, Baranov G, Derbasova N, Chayka T 2017 IOP Conference Series: Materials Science and Engineering "XII International Conference Radiation-Thermal Effects and Processes in Inorganic Materials" 1681 - 6 